\title{
Apatite Formation on Various Silica Gels in a Simulated Body Fluid Containing Excessive Calcium lon
}

\author{
Sung-Baek CHO, Fumiaki MIYAJI, Tadashi KOKUBO, Kazuki NAKANISHI, \\ Naohiro SOGA and Takashi NAKAMURA* \\ Department of Material Chemistry, Faculty of Engineering, Kyoto University, Yoshida-honmachi, Sakyo-ku, Kyoto-shi 606-01 \\ *Department of Orthopaedic Surgery, Faculty of Medicine, Kyoto University, Shogoin-kawaharacho, Sakyo-ku, Kyoto-shi 606-01
}

\author{
カルシウムを過剩に含む擬似体液中における各種シリカゲル表面でのアパタイト形成 \\ 趙 易佰・宮路史明・小久保 正・中西和樹・曾我直弘・中村孝志* \\ 京都大学工学部材料化学教室, 606-01 京都市左京区吉田本町 \\ *京都大学医学部整形外科学教室, 606-01 京都市左京区聖護院川原町
}

\begin{abstract}
It was previously shown that a silica gel prepared in a solution containing polyethylene glycol (SPEG) induces the apatite nucleation in SBF, but those prepared in pure water (S-W) and a solution containing polyacrylic acid (S-PAA) do not induce it. This indicates that a limited type of silanol groups is effective for apatite nucleation. In the present study, apatite-forming ability of these silica gels was examined in SBF containing excessive calcium ion. It was found that all these silica gels formed the apatite on their surfaces in this fluid, although the rate of apatite formation decreased in the order S-PEG $>$ S-PAA $>$ S-W. This indicates that any type of silanol groups has potential for inducing apatite nucleation under this condition. Such environment rich in calcium ion is produced around the surfaces of $\mathrm{CaO}, \mathrm{SiO}_{2}$-based glasses and glass-ceramics when they are implanted into living body. The present results indicate that the $\mathrm{CaO}-\mathrm{SiO}_{2}$ system can be a good basic composition for bioactive glasses and glass-ceramics. [Received September 29, 1995; Accepted January 18, 1996]
\end{abstract}

Key-words : Bioactivity, Silica gel, Hydroxyapatite, Simulated body fluid

\section{Introduction}

It has been shown that bonding of bioactive glasses and glass-ceramics to living bone is achieved through a bonelike apatite layer which is formed on their surfaces in body environment. ${ }^{1)-14)}$ It is , therefore, believed that the prerequisite for glasses and glass-ceramics to bond to bone is the formation of a layer of biologically active bonelike apatite, i.e., carbonate-containing apatite, on their surfaces in the body. ${ }^{15), 16)}$

For the mechanism of apatite formation on the surfaces of bioactive glasses and glass-ceramics, hydrated silica developed on their surfaces in the body has been assumed to induce nucleation of the apatite. ${ }^{17)-20)}$ Actually, it was experimentally confirmed that pure silica gel prepared by hydrolysis and polycondensation of tetraethoxysilane in aqueous solution containing polyethylene glycol induces the formation of the apatite on its surface when the gel is soaked in a simulated body fluid (SBF) with ion concentrations nearly equal to those of human blood plasma. ${ }^{21)-25)}$ The same silica gel heat-treated above $900^{\circ} \mathrm{C}$, however, as well as a pure silica glass synthesized by vapor axial deposition and quartz single crystal synthesized by hydrothermal method did not induce it.21),25) These results suggest that the silanol group formed on the surface of the silica gel heat-treated below $800^{\circ} \mathrm{C}$ in SBF could be responsible for the apatite nucleation.

On the other hand, West and Hench recently proposed on the basis of molecular orbital calculation that not all kind of the silanol groups but only the silanol groups forming trigonal siloxane can induce the apatite nucleation. ${ }^{26)}$ Present authors showed that a pure silica gel prepared in a solution containing polyethylene glycol induces the apatite nucleation in SBF as mentioned above, but those prepared in pure water and a solution containing polyacrylic acid do not induce it. ${ }^{27)}$ These results suggest that only a certain type of structural unit of the silanol groups is effective for the apatite nucleation.

In the present study, apatite formation on the surfaces of various silica gels prepared in different media was investigated in SBF with excessive calcium ion. The result was discussed in terms of the mechanism of apatite nucleation.

\section{Experimental procedure}

\subsection{Gel preparation}

Three kinds of silica gels were prepared by the hydrolysis and polycondensation of tetraethoxysilane (TEOS) in different media. First, $8 \mathrm{~g}$ of three kinds of solutions, i.e., as ion-exchanged distilled water, and those added with $0.6 \mathrm{~g}$ of polyacrylic acid (30000 in an average molecular weight) or $0.7 \mathrm{~g}$ of polyethylene glycol (10000 in an average molecular weight) were prepared. Concentrated nitric acid $\left(\mathrm{HNO}_{3}, 62\right.$ mass\% $)$ in $0.81 \mathrm{~g}$ was added to these solutions. Then $7 \mathrm{ml}$ of TEOS was added to the solutions under vigorous stirring. After stirring for 5 
min, the solutions were transferred into plastic petri dishes with its top tightly sealed, and were kept at $40^{\circ} \mathrm{C}$ in air-circulating oven for gelation for $18 \mathrm{~h}$. The obtained wet gels were immersed in $1 \mathrm{M}$ nitric acid for $6 \mathrm{~h}$ to be washed. In this operation, the polymers contained in the gels were almost leached out. The nitric acid was renewed every $2 \mathrm{~h}$. After being dried at $40^{\circ} \mathrm{C}$ for $6 \mathrm{~d}$, they were heated up to $600^{\circ} \mathrm{C}$ at a rate of $100^{\circ} \mathrm{C} / \mathrm{h}$ and kept at $600^{\circ} \mathrm{C}$ for $2 \mathrm{~h}$, then allowed to cool to room temperature. The silica gels prepared in pure water and aqueous solutions containing polyacrylic acid or polyethylene glycol are hereafter named S-W, S-PAA and S-PEG, respectively.

\subsection{Characterization of gel}

The size of macropore contained in the silica gels were examined by a scanning electron microscope (SEM) (S-2500CX, Hitachi, Ltd., Tokyo, Japan) observation, after gold-palladium film was coated on the surface of the specimens. The volume of pore smaller than $200-\mathrm{nm}$ in diameter and specific surface area were measured with an automatic nitrogen adsorption pore size analyzer (ASAP-2000, Micromeritics, Tokyo, Japan). For the pore volume measurement, the silica gels were degassed at $200^{\circ} \mathrm{C}$ for 30 min under dry nitrogen flow prior to each measurement. The experimental errors in the pore volume measurement were less than $10 \%$ for all the samples. Raman spectroscopy (T64000, JobinYvon, France) was employed to examine the tetrasiloxane D1 defect, trisiloxane D2 defect and silanol groups $(\mathrm{Si}-\mathrm{OH})$ in the gels. All the Raman spectra were obtained using the 514.5-nm line of an $\mathrm{Ar}^{+}$laser in the $180^{\circ}$ reflection configuration.

2.3 Soaking gel in a simulated body fluid

A simulated body fluid ( $\mathrm{SBF} 1.5 \mathrm{Ca}$ ) with excessive calcium ion, i.e., $\mathrm{Ca}$ concentration of which is 1.5 times that of the simulated body fluid (SBF) with ion concentrations nearly equal to those of human blood plasma as given in Table 1, was prepared by dissolving reagents $\mathrm{NaCl}, \mathrm{NaHCO}_{3}, \mathrm{KCl}, \mathrm{K}_{2} \mathrm{HPO}_{4}$. $3 \mathrm{H}_{2} \mathrm{O}, \mathrm{MgCl}_{2} \cdot 6 \mathrm{H}_{2} \mathrm{O}, \mathrm{CaCl}_{2}$ and $\mathrm{Na}_{2} \mathrm{SO}_{4}$ in distilled water. The fluid was buffered at $\mathrm{pH} 7.4$ at $36.5^{\circ} \mathrm{C}$ with $50 \mathrm{mM}$ of tris (hydroxymethyl) aminomethane $\left(\left(\mathrm{CH}_{2} \mathrm{OH}\right)_{3} \mathrm{CNH}_{2}\right)$ and $45 \mathrm{mM}$ hydrochloric acid $(\mathrm{HCl})$ as was reported previously.25) Rectangular specimens of $6 \times 6 \times 1.5 \mathrm{~mm}^{3}$ in size were cut from the gels. For comparison, similar specimens were cut from a highly pure silica glass (Sumiquartz SK1300, Sumitomo Metal Industries Ltd., Tokyo, Japan) synthesized by vapor axial deposition. At

Table 1. Ion Concentrations of SBF and SBF1.5Ca in Comparison with Those of Human Blood Plasma

\begin{tabular}{ccccccccc}
\hline & \multicolumn{8}{c}{ Concentration $/ \mathrm{mM}$} \\
\cline { 2 - 9 } & $\mathrm{Na}^{+}$ & $\mathrm{K}^{+}$ & $\mathrm{Mg}^{2+}$ & $\mathrm{Ca}^{2+}$ & \multicolumn{1}{c}{$\mathrm{Cl}$} & $\mathrm{HCO}_{3}{ }^{\circ}$ & $\mathrm{HPO}_{4}{ }^{2 \cdot}$ & $\mathrm{SO}_{4}{ }^{2 .}$ \\
\hline Blood plasma & 142.0 & 5.0 & 1.5 & 2.5 & 103.0 & 27.0 & 1.0 & 0.5 \\
SBF & 142.0 & 5.0 & 1.5 & 2.5 & 148.8 & 4.2 & 1.0 & 0.5 \\
SBF1.5Ca & 142.0 & 5.0 & 1.5 & 3.75 & 148.8 & 4.2 & 1.0 & 0.5 \\
\hline
\end{tabular}

least, three pieces of each kind of specimen were immersed in $15 \mathrm{ml}$ of SBF1.5Ca. After being soaked in $\mathrm{SBF} 1.5 \mathrm{Ca}$ for various periods, the specimens were removed from the fluid and gently washed with distilled water. The specimens were dried at room temperature.

\subsection{Surface analysis}

Surface structures of the specimens before and after soaking in $\mathrm{SBF} 1.5 \mathrm{Ca}$ were analyzed using thinfilm X-ray diffraction (2651A, Rigaku Co., Tokyo, Japan), Fourier-transformed infrared (FT-IR) reflection spectroscopy (FT-IR5M, JASCO, Tokyo, Japan) and SEM observation. In the X-ray diffraction, the surface of a specimen was fixed at an angle of $1^{\circ}$ against the direction of the incident beam. The FT-IR reflection spectroscopy was performed with the reflection angle of $75^{\circ}$.

\subsection{Measurement of silicon dissolution}

Concentrations of the silicon released from the gels and silica glass into SBF1.5Ca were measured with inductively coupled plasma (ICP) atomic emission spectroscopy (SPS1500VR, Seiko Instruments Inc., Tokyo, Japan). For ICP atomic emission spectroscopy, one milliliter of the solution was drawn from the bottle and added to $10 \mathrm{ml}$ of ion-exchanged distilled water.

\section{Results}

Figure 1 shows the Raman spectra of the surfaces of various silica gels prepared in different media, and silica glass. On the basis of the previous study, each observed Raman peak is assigned as follows. ${ }^{28)}$ The broad weak peaks at about 800 and $1070 \mathrm{~cm}^{-1}$ are assigned to a mode of $\mathrm{Si}-\mathrm{O}-\mathrm{Si}$ symmetric stretching vibration and a transverse optical (TO) mode of $\mathrm{Si}-\mathrm{O}$ asymmetric stretching vibration, respectively. The broad large peak at about $430 \mathrm{~cm}^{-1}$ is assigned to a symmetric ring-breathing mode involving mainly oxygen motion. The sharp peaks at 495 and 605 $\mathrm{cm}^{-1}$ are assigned to tetrasiloxane D1 defect and trisiloxane D2 defect, respectively. The $980 \mathrm{~cm}^{-1}$

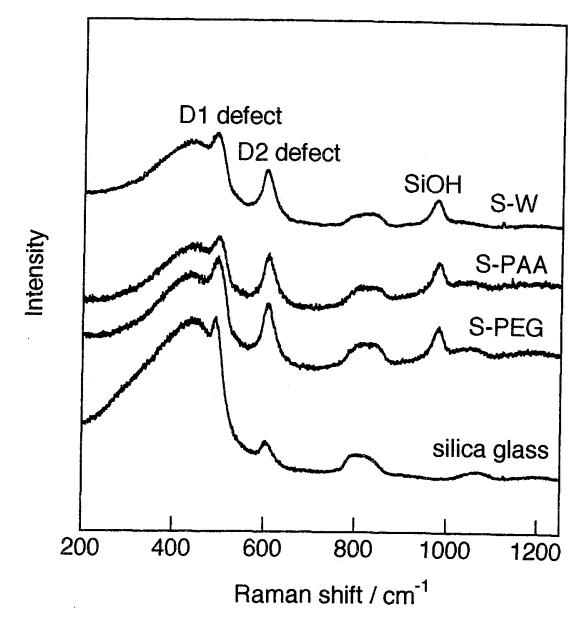

Fig. 1. Raman spectra of the surfaces of various silica gels prepared in different media and silica glass. 
peak is assigned to bulk $\mathrm{Si}-\mathrm{OH}$ stretching vibration. It can be seen from Fig. 1 that the intensity of the $980 \mathrm{~cm}^{-1}$-peak ascribed to $\mathrm{Si}-\mathrm{OH}$ stretching vibration of silica gels is almost same irrespective of kind of media used in preparation, whereas the peak is not observed for silica glass. This indicates that all the silica gels contain a large amount of silanol

Table 2. Microstructures of the Silica Gels

\begin{tabular}{|c|c|c|c|c|c|}
\hline \multirow[t]{2}{*}{ Gel } & \multirow{2}{*}{$\begin{array}{l}\text { Medium } \\
\text { for } \\
\text { gel preparation }\end{array}$} & \multirow{2}{*}{$\begin{array}{l}\text { Size of } \\
\text { macropore } \\
(\mu \mathrm{m})\end{array}$} & \multicolumn{2}{|c|}{$\begin{array}{l}\text { Volume of } \\
\text { pore }\left(\mathrm{cm}^{3} / \mathrm{g}\right)\end{array}$} & \multirow{2}{*}{$\begin{array}{l}\text { Specific } \\
\text { surface } \\
\text { area }\left(\mathrm{cm}^{2} / \mathrm{g}\right)\end{array}$} \\
\hline & & & "micro- & **meso- & \\
\hline S-W & $\mathrm{H}_{2} \mathrm{O}$ & - & 0.0 & 0.5710 & 836.52 \\
\hline S-PAA & $\mathrm{H}_{2} \mathrm{O}+\mathrm{PAA}$ & 1 & 0.0 & 0.3841 & 626.79 \\
\hline S-PEG & $\mathrm{H}_{2} \mathrm{O}+\mathrm{PEG}$ & 2 & 0.106 & 0.2752 & 680.83 \\
\hline
\end{tabular}

${ }^{*}$ pores with size less than $1.7 \mathrm{~nm}$

${ }^{* *}$ pores with size ranging $1.7-200 \mathrm{~nm}$
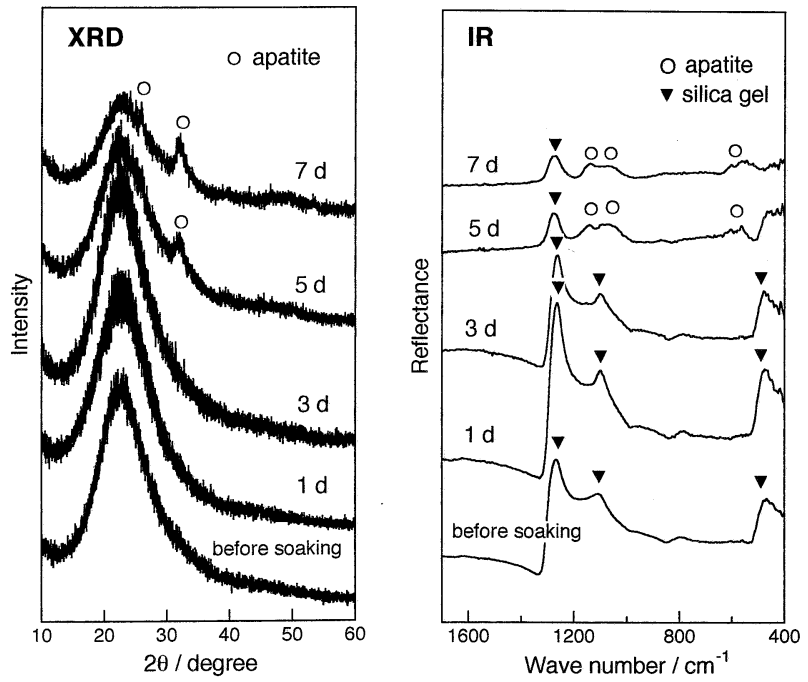

Fig. 2. Thin-film X-ray diffraction patterns and FT-IR reflection spectra of the surface of $\mathrm{S}-\mathrm{W}$ gel soaked in SBF1.5Ca for various periods.
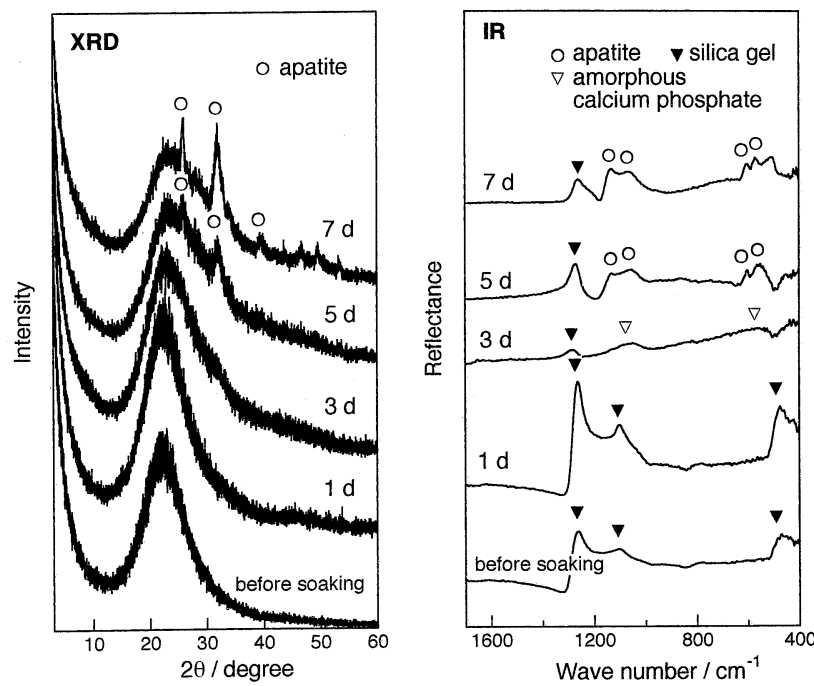

Fig. 3. Thin-film X-ray diffraction patterns and FT-IR reflection spectra of the surface of S-PAA gel in SBF1.5Ca for various periods. groups on their surfaces irrespective of the preparation history, although silica glass does not.

The microstructures of the silica gels are summarized in Table 2. The S-PAA and S-PEG gels have interconnected macropores in micrometer-size, whereas the S-W gel does not have it. The size of macropores of the S-PAA and S-PEG gels are about 1 and $2 \mu \mathrm{m}$ in diameter, respectively. ${ }^{27)}$ Among the gels, the S-W and S-PAA gels have only mesopore ranging $1.7-200 \mathrm{~nm}$, whereas the S-PEG gel has micropores less than $1.7 \mathrm{~nm}$ in addition to the mesopore. The volume of mesopore decreased in the order $\mathrm{S}-\mathrm{W}>\mathrm{S}-\mathrm{PAA}>\mathrm{S}-\mathrm{PEG}$. The specific surface area is considerably larger in the $\mathrm{S}-\mathrm{W}$ gel than in the S-PAA and S-PEG gels.

Figures 2, 3, 4 and 5 show the thin-film X-ray diffraction patterns and FT-IR reflection spectra of
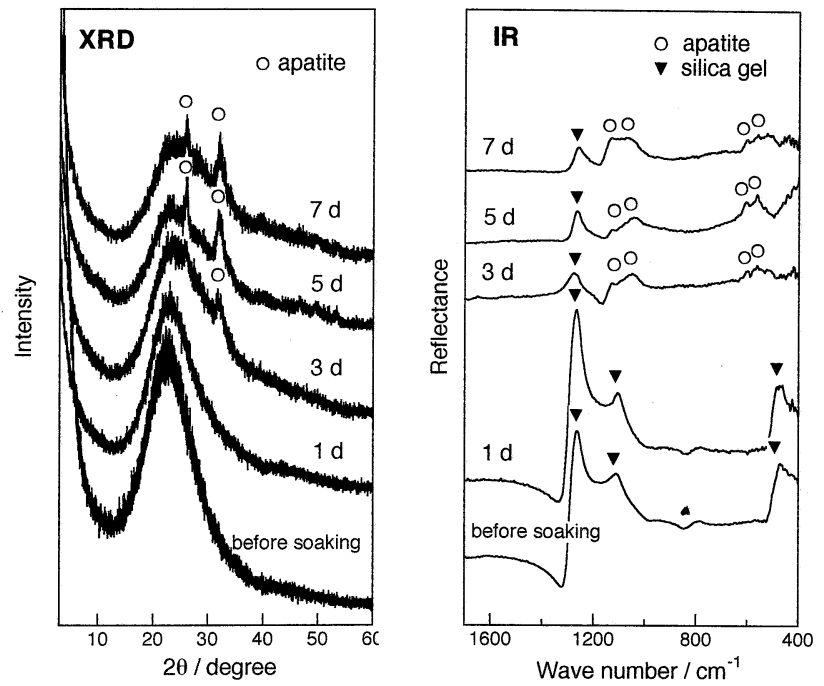

Fig. 4. Thin-film X-ray diffraction patterns and FT-IR reflection spectra of the surface of S-PEG gel soaked in SBF1.5Ca for various periods.
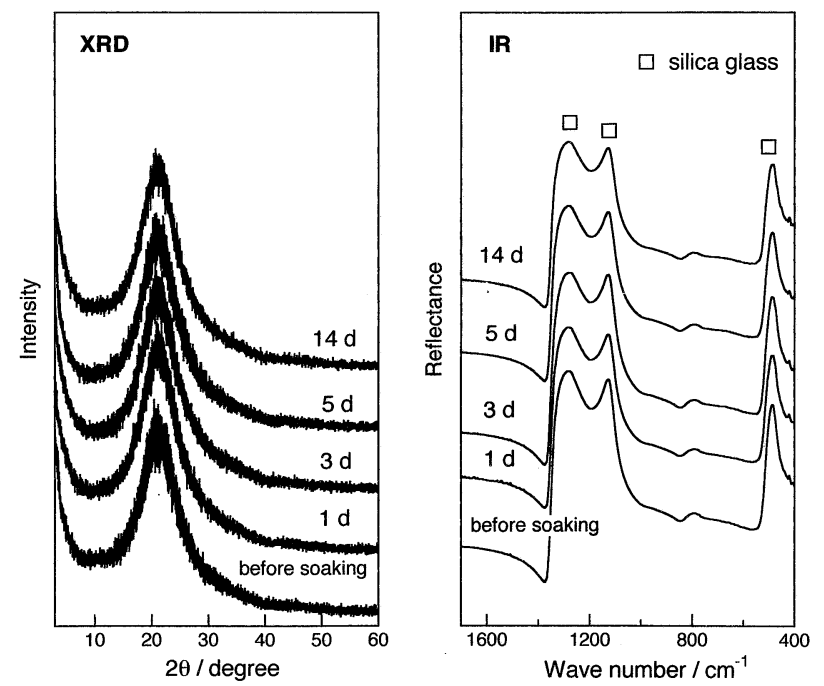

Fig. 5. Thin-film X-ray diffraction patterns and FT-IR reflection spectra of the surface of silica glass soaked in SBF1.5Ca for various periods. 
the surfaces of various silica gels and silica glass soaked in $\mathrm{SBF} 1.5 \mathrm{Ca}$ for various periods, respectively. Assignment of main peaks based on the previous papers ${ }^{9), 20)}$ are also shown in Figs. 2, 3, 4 and 5. Figure 2 shows that no new phase appears after soaking for $3 \mathrm{~d}$ and an apatite begins to form on the $\mathrm{S}-\mathrm{W}$ gel after soaking for $5 \mathrm{~d}$. On the other hand, Fig. 3 shows that amorphous calcium phosphate forms on the S-PAA gel after the soaking for $3 \mathrm{~d}$, and it transforms into the crystalline apatite and it grows with increasing soaking period. It can be seen from Fig. 4 that the apatite is formed on the S-PEG gel within 3 $\mathrm{d}$ and it grows with increasing soaking period. Silica glass, however, did not form the apatite on its surface in SBF1.5Ca even after the soaking for 2 weeks as shown in Fig. 5.

Figures 6 and 7 show the SEM photographs of the surfaces of various silica gels soaked in $\mathrm{SBF} 1.5 \mathrm{Ca}$ for 3 and $7 \mathrm{~d}$, respectively. It can be seen from Fig. 6 that a leaflike particles are deposited on the surfaces of the S-PAA and S-PEG gels, whereas no such particles are deposited on the $\mathrm{S}-\mathrm{W}$ gel. The morphology of the leaflike particles deposited on the S-PEG gel is much clearly observed compared with that of SPAA gel. That is, the particles deposited on the surface of the S-PEG gel are well crystallized rather than those on the surface of the S-PAA gel. After the soaking in $\mathrm{SBF} 1.5 \mathrm{Ca}$ for $7 \mathrm{~d}$, the leaflike particles are deposited on the surfaces of all the silica gels, as shown in Fig. 7. The morphology of such leaflike particles is quite similar to that of the apatite formed on the surfaces of bioactive glasses and glass-ceramics. ${ }^{9), 20)}$ The results of SEM observation

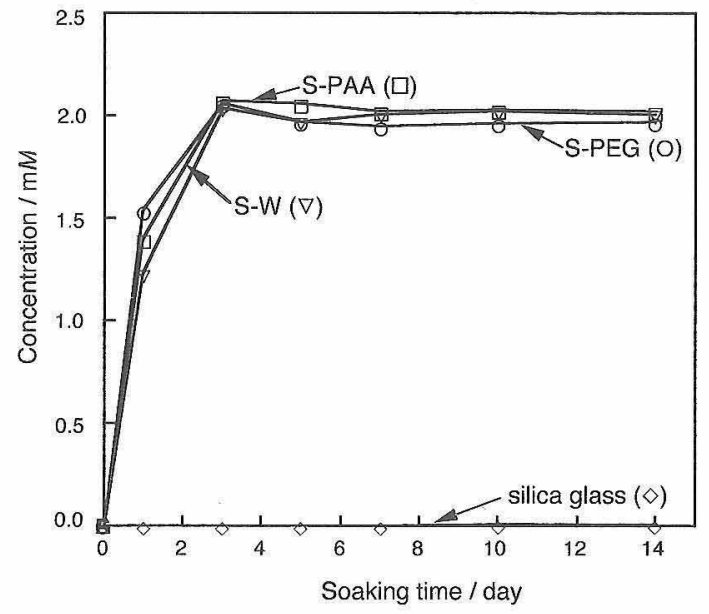

Fig. 8. Changes in silicon concentration of the SBF1.5Ca due to the soaking of various silica gels and silica glass as a function of soaking time.
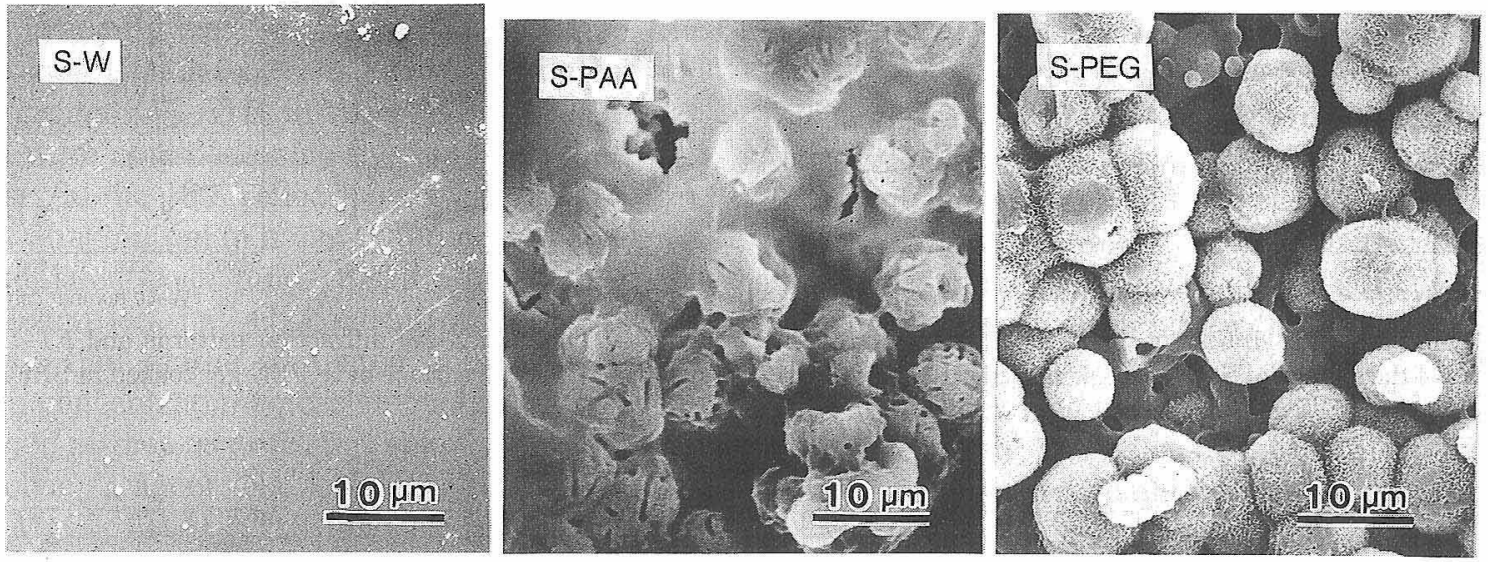

Fig. 6. SEM photographs of the surfaces of various silica gels soaked in SBF1.5Ca for $3 \mathrm{~d}$.
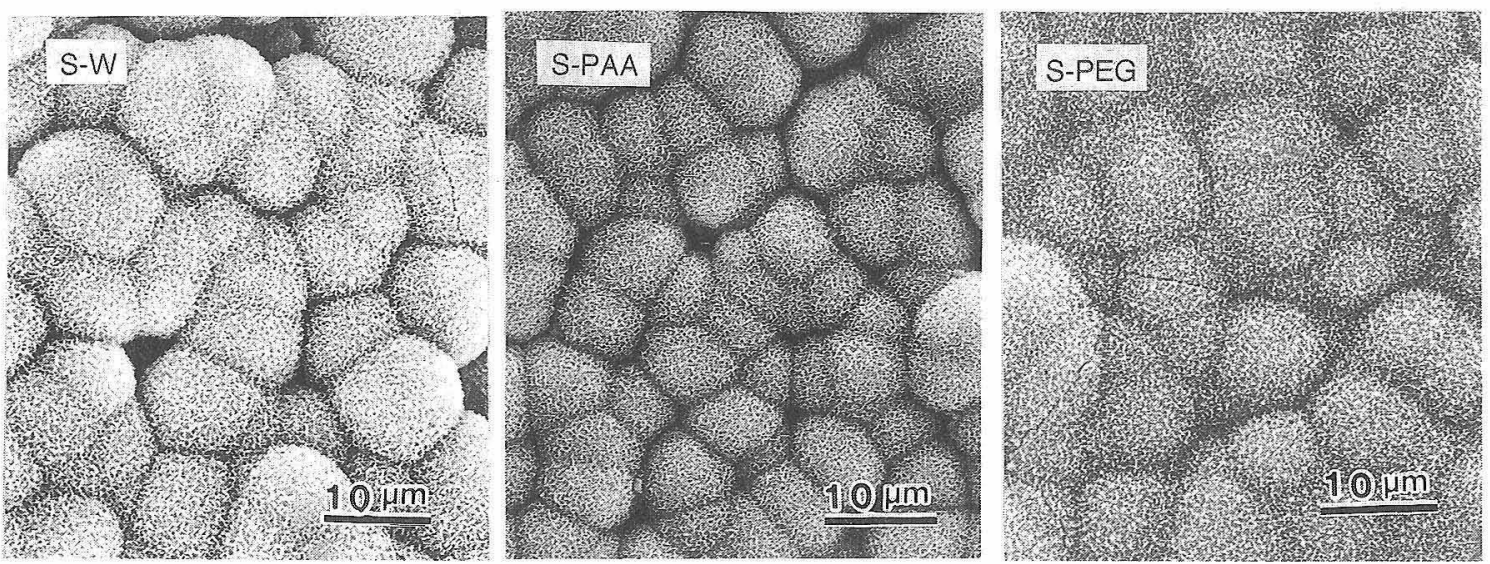

Fig. 7. SEM photographs of the surfaces of various silica gels soaked in SBF1.5Ca for $7 \mathrm{~d}$. 
as well as thin film X-ray diffraction and FT-IR spectroscopy indicate that apatite-forming ability of the silica gels decreases in the order S-PEG $>$ S$\mathrm{PAA}>\mathrm{S}-\mathrm{W}$.

Figure 8 shows the changes in silicon concentration of SBF1.5Ca due to the soaking of various silica gels and silica glass as a function of soaking time. It can be seen from Fig. 8 that all the examined silica gels show the steep increase in silicon concentration up to about $4 \mathrm{~d}$, and it reached about $2 \mathrm{mM}$, which is the solubility of the silica in water, ${ }^{29)}$ whereas the silica glass shows almost no increase in silicon concentration. The behavior of release of silicon from the various silica gels into $\mathrm{SBF} 1.5 \mathrm{Ca}$ is similar to the case of the same gels when soaked in the SBF. ${ }^{27}$ )

\section{Discussion}

The previous study showed that among the silica gels examined in the present study, only S-PEG gel forms the bonelike apatite on its surface in SBF. ${ }^{27)}$ In contrast with this, the present study showed that all the examined silica gels form it on their surfaces in $\mathrm{SBF} 1.5 \mathrm{Ca}$, although the rate of the apatite formation decreased in the order S-PEG $>$ S-PAA $>$ S-W. The silica glass did not form the apatite on it both in $\mathrm{SBF}$ and SBF1.5Ca. These results are interpreted as follows.

The rate, $I$, of nucleation of a crystal on a substrate in a supersaturated solution at temperature, $T$, is generally given by the following equation ${ }^{30)}$

$$
I=I_{0} \exp \left(\frac{-\Delta G^{*}}{k T}\right) \exp \left(\frac{-\Delta G_{\mathrm{m}}}{k T}\right)
$$

where $I_{0}$ is a constant, $k$ the Boltzmann constant, $\Delta G^{*}$ the free energy for formation of an embryo of critical size, and $\Delta G_{\mathrm{m}}$ the activation energy for transport across the nucleus-solution interface. The free energy $\Delta G^{*}$ is given by the equation

$$
\Delta G^{*}=\frac{16 \sigma^{3} f(\theta)}{3\left(k T / V_{\beta} \ln \left(I P / K_{0}\right)\right)^{2}}
$$

where $\sigma$ is an interface energy between the nucleus and the solution, $I P$ the ionic activity product of the crystal in the solution, $K_{0}$ the value of $I P$ at equilibrium, i.e., solubility product of the crystal, $f(\theta)$ a function of contact angle between the nucleus and the substrate, and $V_{\beta}$ the molecular volume of the crystal phase.

In discussing the dependence of the apatite nucleation rate on the kind of substrate and solution, $V_{\beta}$ is constant, and $\Delta G_{\mathrm{m}}, \sigma$ and $K_{0}$ are assumed to be almost equal between in SBF and in SBF1.5Ca. The ionic activity product IP of the apatite varies with the kind of the solution and $f(\theta)$ varies with the kind of the substrate. The former is given by the following equation ${ }^{20)}$

$$
\begin{aligned}
I P= & \left(\gamma_{\mathrm{Ca}^{2+}}\right)^{10}\left(\gamma_{\mathrm{PO}_{4}^{3-}}\right)^{6}\left(\gamma_{\mathrm{OH}^{-}}\right)^{2} \\
& {\left[\mathrm{Ca}^{2+}\right]^{10}\left[\mathrm{PO}_{4}^{3-}\right]^{6}\left[\mathrm{OH}^{-}\right]^{2} }
\end{aligned}
$$

where $\gamma$ is the activity coefficient and square bracket is the concentration of each ion, since the formation of the hydroxyapatite is given by the following equation.

$$
\begin{gathered}
10 \mathrm{Ca}^{2+}+6 \mathrm{PO}_{4}^{3-}+2 \mathrm{OH}^{-} \\
=\mathrm{Ca}_{10}\left(\mathrm{PO}_{4}\right)_{6}(\mathrm{OH})_{2}
\end{gathered}
$$

The IP of the apatite calculated for SBF and SBF1.5 Ca are $2.12 \times 10^{-96}$ and $8.97 \times 10^{-95}$, respectively. The $K_{0}$ of the apatite in an aqueous solution is reported to be $5.5 \times 10^{-118}$ at $37^{\circ} \mathrm{C} .^{31)}$ This means that both $\mathrm{SBF}$ and $\mathrm{SBF} 1.5 \mathrm{Ca}$ are highly supersaturated with respect to the apatite and the degree of the supersaturation is higher in SBF1.5Ca than in SBF. Therefore, SBF1.5Ca gives higher apatite nucleation rate for all the substrates than SBF. This is the reason why all the examined gels formed the apatite on their surfaces in SBF1.5Ca whereas only S-PEG gel formed it in SBF.

Even under such favorable environment, the apatite-forming ability largely varied with the substrates. It decreased in the order S-PEG $>$ S$\mathrm{PAA}>\mathrm{S}-\mathrm{W} \gg$ silica glass. This difference attributed to the difference in $f(\theta)$ among the substrates, because other parameters in Eq. (2) are constant. The function $f(\theta)$ for the silica glass is almost 1 , since the silica glass did not induce the heterogeneous nucleation. Those for the silica gels are considerably less than 1 and decrease in the order S-W $>$ S-PAA $>$ SPEG. The surface electrochemical properties such as zeta potential might affect the $f(\theta)$ value, although there is no evidence at present.

It is important in practical applications to know that the silica gel provides fairly low $f(\theta)$ against the apatite, irrespective of its structure, and can induce the heterogeneous nucleation of the apatite, even if it is in an environment rich in calcium. Such an environment is easily achieved around the surfaces of $\mathrm{CaO}$, $\mathrm{SiO}_{2}$-based glasses and glass-ceramics when they are implanted into a living body. The calcium ion released from the glasses and glass-ceramics increases the degree of the supersaturation of the surrounding fluid with respective to the apatite, and a hydrated silica formed on their surfaces induces the apatite nucleation. Therefore, the present result indicates that the $\mathrm{CaO}-\mathrm{SiO}_{2}$ system can be good basic composition of bioactive glasses and glass-ceramics. This prediction is consistent with the previous finding that in the system $\mathrm{CaO}-\mathrm{SiO}_{2}-\mathrm{P}_{2} \mathrm{O}_{5}, \mathrm{CaO}, \mathrm{SiO}_{2}$ based glasses forms the bonelike apatite on them in $\mathrm{SBF}$ whereas $\mathrm{CaO}, \mathrm{P}_{2} \mathrm{O}_{5}$-based glasses do not form it. ${ }^{20)}$

The appreciably lower $f(\theta)$ for the silica gels in comparison with the silica glass indicates that these silica gels provide favorable sites for the apatite nucleation, but the silica glass does not it. According to the Raman spectra in Fig. 1, the silica gels have a lot of silanol ( $\mathrm{Si}-\mathrm{OH}$ ) groups on their surfaces, whereas the silica glass has not it. On the other hand, Fig. 8 shows that the silica gels dissolve into SBF1.5 $\mathrm{Ca}$ at high rates, whereas the silica glass little dis- 
solves. This indicates that silanol groups are formed on the surfaces of the silica gels furthermore after the soaking in $\mathrm{SBF} 1.5 \mathrm{Ca}$, since the dissolution proceeds via hydrolysis of $\mathrm{SiO}_{2}$, whereas it is not formed on that of the silica glass even after the soaking. In view of these facts, it is believed that the silanol groups abundant on the surfaces of the silica gels are responsible for the apatite nucleation. All the silanol groups, however, have unequal ability for the apatite nucleation, since the apatite-forming ability varied with the kind of the gels.

\section{Summary}

Apatite formation on the surfaces of various silica gels prepared in different media and silica glass was investigated in SBF1.5Ca. After the soaking in SBF1.5Ca for $7 \mathrm{~d}$, the bonelike apatite was formed on the surfaces of all the silica gels having abundant silanol groups. It was not, however, formed on the surface of the silica glass having little silanol groups even after the soaking for 2 weeks. From the results, it can be concluded that all the kind of silanol groups developed on the silica gels can induce the apatite nucleation, although there is some differences in their nucleating abilities. It is interesting to know what type of the silanol groups is most effective for the apatite nucleation. Unfortunately, however, $\mathrm{Ra}$ man spectra in Fig. 1 give no information about difference in surface structure among the gels. Further study is needed for revealing the most effective structural unit.

Acknowledgment This study was supported by a Grant-inAid for Scientific Research of the Asahi Glass Foundation in 1994.

\section{Reference}

1) L. L. Hench and A. E. Clark, "Biocompatibility of Orthopedic Implant, Vol. 2", Ed. by D. F. Wiliams, CRC Press, Boca Raton (1982) pp. 129-70.

2) T. Kitsugi, T. Yamamuro, T. Nakamura, S. Higashi, Y. Kakutani, K. Hyakuna, S. Ito, T. Kokubo, M. Takagi and T. Shibuya, J. Biomed. Mater. Res., 20, 1295-307 (1986).

3) T. Kitsugi, T. Nakamura, T. Yamamuro, T. Kokubo, T. Shibuya and M. Takagi, J. Biomed. Mater.Res., 21, 1255-71 (1987).

4) O. H. Anderson, K. H. Karlsson, K. Kangasniemi and A. Yli-Urpo, Glastechn. Ber., 61, 300-05 (1988).

5) T. Kitsugi, T. Yamamuro, T. Nakamura and T. Kokubo, $J$ Biomed. Mater. Res., 23, 631-48 (1989).

6) G. Berger, F. Sauer, G. Steinborn, F. G. Wihsmann, V. Thieme, St. Kohler and H. Dressel, "Proceedings of XV International Congress on Glass, Vol. 3a”, Ed. by O. V. Mazurin, Nauka, Leningrad (1989) pp. 120-26.

7) T. Kitsugi, T. Yamamuro, T. Nakamura and T. Kokubo, In ternational Orthopaedics (SICOT), 13, 199-206 (1989).
8) T. Kokubo, S. Ito, Z. T. Huang, T. Hayashi, S. Sakka, T. Kitsugi and T. Yamamuro, J. Biomed. Mater. Res., 24, 33143 (1990).

9) T. Kokubo, J. Non-Cryst. Solids, 120, 138-51 (1990).

10) T. Kokubo, "Handbook of Bioactive Ceramics, Vol. 1, Bioactive Glasses and Glass-Ceramics”, Ed. By T. Yamamuro, L. L. Hench and J. Wilson, CRC Press, Boca Raton, FL (1990) pp. 41-49.

11) T. Kokubo, C. Ohtsuki, S. Kotani, T. Kitsugi and T. Yamamuro, "Bioceramics, Vol. 2", Ed. by G. Heimke, Germany Ceramic Society, Cologne (1990) pp. 113-20.

12) K. Ohura, T. Yamamuro, T. Nakamura, T. Kokubo, Y. Ebisawa, Y. Kotoura and M. Oka, J. Biomed. Mater. Res. 25, 357-65 (1991).

13) C. Ohtsuki, H. Kushitani, T. Kokubo, S. Kotani and T. Yamamuro, J. Biomed. Mater. Res., 25, 1363-70 (1991).

14) M. Neo, T. Nakamura, T. Yamamuro, C. Ohtsuki and T. Kokubo, "Bone Bonding Biomaterials", Ed. by P. Ducheyne, T. Kokubo and C.A. van Blitterswijk, Reed Healthcare Communications, Leiderdrop, The Netherlands (1993) pp. 111-21.

15) T. Kokubo, Biomaterials, 12, 155-63 (1991).

16) L. L. Hench, J. Am. Ceram. Soc., 74, 1487-510 (1991).

17) L. L. Hench, "Bioceramics: Material Characteristics versus in vivo Behavior", Ed. by P. Ducheyne and J. Lemons, Annual of New York Academy of Science, Vol. 523, New York (1988) pp. 54-71.

18) K. H. Karlsson, K. Froberg and T. Ringbom, J. Non-Cryst. Solids, 112, 69-72 (1989).

19) C. Ohtsuki, T. Kokubo, K. Takatsuka and T. Yamamuro, $J$. Ceram. Soc. Japan, 99, 1-6 (1991).

20) C. Ohtsuki, T. Kokubo and T. Yamamuro, J. Non-Cryst. Solids, 143, 84-92 (1992).

21) P. Li, C. Ohtsuki, T. Kokubo, K. Nakanishi, N. Soga, T. Nakamura and T. Yamamuro, J. Am. Ceram. Soc., 75, 209497 (1992).

22) P. Li, C. Ohtsuki, T. Kokubo, K. Nakanishi, N. Soga, T. Nakamura and T. Yamamuro, J. Appl. Biomater., 4, 221-29 (1993).

23) P. Li, C. Ohtsuki, T. Kokubo, K. Nakanishi, N. Soga, T. Nakamura and T. Yamamuro, J. Mater. Sci.: Medicine, 4, 127-31 (1993).

24) P. Li, T. Kokubo, K. Nakanishi and K. de Groot, Biomaterials, 14, 963-68 (1993).

25) S. B. Cho, K. Nakanishi, T. Kokubo, N. Soga, C. Otsuki, T. Nakamura, T. Kitsugi and T. Yamamuro, J. Am. Ceram. Soc., 78, 1769-74 (1995).

26) J. H West and L. L. Hench, “Bioceramics, Vol. 5", Ed. by T. Yamamuro, T. Kokubo and T. Nakamura, Kobunshi Kankokai, Kyoto (1991) pp. 75-86.

27) S.B. Cho, K. Nakanishi, T. Kokubo, N. Soga, C. Ohtsuki and T. Nakamura, J. Appl. Biomater., submitted.

28) A. E. Geissberger and F. L.Galeener, Phys. Rev. B., 28, 3266-71 (1983).

29) R. K. Iler, "The Chemistry of Silica", John Wiley \& Sons, New York (1979) p. 40.

30) W. D. Kingery, H. K. Bowen and D. R. Bowen, "Introduction to Ceramics”, John Wiley \& Sons, New York (1960) p. 328.

31) H. McDowell, T. M. Gregory and W. E. Brown, J. Res. Nat. Bur. Stand., 81A, 273-81 (1977). 